Efficient Vol 1 (2) (2018): 157-166. DOI: https://doi.org/10.15294/efficient.vii2.27617
Indonesian Journal of Development Economics
http: https://journal.unnes.ac.id/sju/index.php/efficient

\title{
Studi Pariwisata Kabupaten Magelang, Kota Surakarta dan Kota Semarang Beserta Strategi Pengembangannya
}

\author{
Muhammad Andi Hakim $^{1}$, Fafurida ${ }^{2}$ \\ Jurusan Ekonomi Pembangunan,Fakultas Ekonomi, Universitas Negeri Semarang \\ Permalink/DOI: https://doi.org/10.15294/efficient.vii2.27617 \\ Received: January 2018; Accepted: March 2018; Published: Juny 2018
}

\begin{abstract}
This research is conducted in order to know what makes tourists to visit tourist destinations. The purpose of this study describes the condition and potential of tourist attraction, knowing the factors that influence tourists in deciding tourist destinations, and develop appropriate tourism development strategies. Respondents in this study were the visitors who came to Magelang regency, Surakarta city, and Semarang city as the research location and 7 keyperson from the related offices. The research method used is descriptive analysis, regression analysis and AHP. The results of the study is known that the condition and potential of tourism that has not been managed optimally. The result of regression analysis is known tourist attraction and Community Participation influence the decision of tourists in determining tourist destinations in Magelang regency. In Kota Surakarta, accessibility of infrastructure and community participation influences the decision of tourists in determining tourist destinations. While the city of Semarang tourist attraction influence the decision of tourists in determining tourist destinations. The results of the Analysis Hierarchy Process (AHP) is composed of several priority program criteria, namely the first aspect of transportation availability, the two aspects of cultural resources, the three aspects of natural resources.
\end{abstract}

\section{Keywords: Tourism, Strategy development, Traveler}

\begin{abstract}
Abstrak
Penelitian ini dilakukan dalam rangka mengetahui hal apa yang membuat wisatawan mengunjungi destinasi wisata. Tujuan dari penelitian ini menggambarkan kondisi dan potensi daya tarik wisata, mengetahui faktor yang mempengaruhi wisatawan dalam memutuskan destinasi wisata, serta menyusun strategi pengembangan pariwisata yang tepat. Responden pada penelitian ini adalah para pengunjung yang datang di obyek wisata Kabupaten Magelang, Kota Surakarta, dan Kota Semarang sebagai lokasi penelitian serta 7 keyperson dari dinas terkait. Adapun metode penelitian yang digunakan adalah analisis deskriptif, analisis regresi dan AHP. Hasil penelitian diketahui kondisi dan potensi pariwisata yang ada belum terkelola secara maksimal. Hasil analisis regresi diketahui daya tarik wisata dan Partisipasi Masyarakat mempengaruhi keputusan wisatawan dalam menentukan destinasi wisata di Kabupaten Magelang. Pada Kota Surakarta aksesbilitas sarana prasarana dan partisipasi masyarakat mempengaruhi keputusan wisatawan dalam menentukan destinasi wisata. Sedangkan Kota Semarang daya tarik wisata mempengaruhi keputusan wisatawan dalam menentukan destinasi wisata. Adapun hasil Analysis Hierarchy Process (AHP) tersusun atas beberapa kriteria program yang di prioritaskan yaitu pertama aspek ketersediaan transportasi, kedua aspek sumber daya budaya, ketiga aspek sumber daya alam.
\end{abstract}

\section{Kata Kunci: Pariwisata; Strategi Pengembangan; Wisatawan}

How to Cite:

Hakim, M., \& Fafurida, F. (2018). Studi Pariwisata Kabupaten Magelang, Kota Surakarta dan Kota Semarang Beserta Strategi Pengembangannya. EFFICIENT Indonesian Journal of Development Economics, 1(2), 157-166. https://doi.org/10.15294/efficient.vii2.27617

(C) 2018 Semarang State University. All rights reserved

Alamat Korespondensi :

Alamat: Gedung L2 Lantai 2 FE Unnes

Kampus Sekaran, Gunungpati, Semarang, 50229

E-mail : jurnalefficient@gmail.com 


\section{PENDAHULUAN}

Pariwisata merupakan salah satu sumber devisa negara yang sangat potensial yang mempunyai pengaruh besar dalam membangun perekonomian. Dilihat dari penerimaan devisa, PDB, dan penyerapan tenaga kerja yang semakin meningkat, sektor pariwisata nampaknya memberikan kontribusi yang cukup besar bagi

pembangunan perekonomian Indonesia. Pariwisata juga menimbulkan efek pengganda baik secara langsung yaitu penyerapan tenaga kerja dalam sektor pariwisata maupun dampak tidak langsung berupa perkembangan kegiatan ekonomi pendukung pariwisata seperti hotel, rumah makan, jasa transportasi dan lai-lain. Kunjungan wisatawan ke daerah tujuan wisata dipengaruhi oleh beberapa faktor antara lain pengaruh obyek wisata itu sendiri misalnya daya tarik wisata, lokasi, promosi, dan pelayanan, selain itu juga terdapat factor yang berasal dari pengunjung sendiri seperti selera pengunjung, pendapatan, jarak tempuh perjalanan. Dalam UU No. 10 tahun 2009 tentang Kepariwisataan ditegaskan bahwa daya tarik wisata adalah segala sesuatu yang memiliki keunikan, keindahan, dan nilai yang berupa keanekaragaman kekayaan alam, budaya, dan hasil buatan manusia yang menjadi sasaran atau tujuan kunjungan wisatawan. Daya tarik wisata pada daerah tujuan wisata tertentu akan menjadi daya saing apabila daerah tujuan wisata tersebut lebih baik dibandingkan daerah tujuan wisata lainnya.

Dalam perkembangan pariwisata saat ini, Wisatawan di Indonesia senang mencari tempat yang unik untuk digunakan berfoto foto dengan berkunjung ke daya tarik wisata yang diminati. Daya tarik wisata sendiri di Indonesia sangatlah banyak dikarenakan wilayah Indonesia yang sangat luas, akan tetapi masih banyak yang belum terekspos ke masyarakat padahal daya tarik wisata tersebut memiliki potensi yang bagus untuk dikembangkan. Kota Semarang sendiri sebagai pusat ibukota pemerintahan Jawa Tengah memiliki banyak tempat obyek wisata yang bagus dan menarik. Akan tetapi pengelolaannya yang tidak tepat serta kurangnya ekspos dari pemerintah terkait membuat minat berkunjung masih sedikit.

Masalah dalam penelitian ini adalah bagaimana kondisi sarana dan prasarana penunjang pariwisata di Jawa Tengah khususnya Di Kota Semarang, Kota Surakarta dan Kabupaten Magelang dengan jumlah kunjungan wisata terbanyak pada tahun 2015. Selain itu faktor apa saja yang membuat seorang wisatawan lebih memilih berkunjung ke salah satu daerah destinasi wisata ketimbang daerah wisata lainnya. Seperti dalam masalah yang ada dalam penelitian ini, Jika dibandingkan dengan Kota Surakarta dan Kabupaten Magelang. Kota Semarang sendiri memiliki banyak pilihan tempat wisata mulai dari wisata alam, edukasi, kuliner, belanja, budaya dan masih banyak lagi. Serta event wisata yang setiap bulannya ada di Kota Semarang. Akan tetapi setiap tahunnya jumlah wisatawan yang berkunjung di Kota Semarang masih kalah ketimbang Kota Surakarta dan Kabupaten Magelang.

\section{METODE PENELITIAN}

Jenis penelitian yang digunakan dalam penelitian ini adalah jenis penelitian kualitatif dengan menggunakan metode analisis deskriptif, analisis regresi dan Analisis Hierarki Proses (AHP). Metode analisis deskriptif digunakan untuk mengetahui kondisi dan potensi daya tarik wisata yang ada. Metode analisis regresi digunakan untuk mengetahui keputusan wisatawan dalam menentukan destinasi wisata. Sedangkan, Analisis Hierarki Proses (AHP) untuk 
mengetahui strategi yang harus dilakukan dalam pengembangan destinasi wisata di Kabupaten Magelang Kota Surakarta dan Kota Semarang.

Sumber data yang digunakan dalam penelitian ini berasal dari: (1) Data Primer diperoleh dari hasil wawancara dan kuesioner ,

(2) Data Sekunder diperoleh dari dokumen publikasi atau laporan penelitian dari dinas atau instansi maupun sumber data lainnya yang menunjang.

Data primer diperoleh dari narasumber yang merupakan unsur masyarakat yang merupakan pengunjung tempat wisata dengan jumlah 300 orang serta dari unsur pemerintah berjumlah 8 orang dengan melakukan wawancara. Selain itu, data primer juga diperoleh dari keyperson untuk perumusan kebijakan dalam Analisis Hierarki Proses (AHP) yang diperoleh juga dari unsur pemerintah Dinas Pariwisata dan Kebudayaan Provinsi Jawa Tengah dan Dinas Pariwisata dan Kebudayaan yang berada di Kabupaten Magelang Kota Surakarta Dan Kota Semarang dengan menggunakan angket atau kuesioner AHP. Keyperson tersebut ditentukan berdasarkan kriteria kepakaran dan keterlibatannya dalam upaya pengembangan destinasi wisata.

\section{HASIL DAN PEMBAHASAN}

$\begin{array}{clr}\text { Kabupaten } & \text { Magelang merupakan } \\ \text { kabupaten yang menghubungkan antara }\end{array}$
Yogyakarta dan Semarang, yang notabene kedua kota tersebut merupakan kota besar. Letak Kabupaten Magelang sendiri sangatlah strategis, pasalnya terletak di dalam jalur utama yang menghubungkan kedua kota besar tersebut. Dari letak yang strategis itulah potensi-potensi besar bisa dikembangkan di "Kota Sejuta Bunga" tersebut. Rata rata kunjungan wisatawan setiap bulannya lebih dari 300 orang. Candi Borobudur masih menjadi primadona wisatawan untuk berkunjung ke Kabupaten magelang dengan rata rata kunjungan wisatawan mencapai 298.198 orang setiap bulannya. Di urutan berikutnya terdapat Ketep Pass dengan jumlah kunjungan wisatawannya mencapai 29.507 orang sedangkan diurutan paling terakhir terdapat Air Terjun Sumuran Seloprojo dengan jumlah kunjungan per bulannya 365 orang.

Lain halnya dengan Kabupaten Magelang. Kota Surakarta atau yang lebih kerap disapa dengan Kota Solo memiliki potensi yang sangat besar untuk menjadi salah satu (meeting, incentive, convention, exhibition city) di Indonesia. Mulai dari potensi budaya, pariwisata, sampai perdagangan, semua dikelola dengan baik oleh pemerintah Kota Surakarta. Kota Solo merupakan salah satu kota di Jawa tengah yang masih sangat lekat dengan kebudayaan Jawanya. Sebagai Kota Budaya dan sebagai “Solo The Spirit Of Java” kebijakan Pemerintah Kota Surakarta yang sangat ramah terhadap kegiatan usaha sangat membuka peluang ekonomi baru bagi warganya sendiri maupun bagi investor. Hal itu membuat Solo menjadi kota yang sangat terbuka terhadap dunia usaha, khususnya dalam perdagangan mulai yang berskala besar berupa mal dan pasar swalayan yang mendatangkan investor ke kota Solo. Kota Solo sendiri mempunyai fasilitas transportasi, fasilitas pendidikan, fasilitas kesehatan, fasilitas perbelanjaan, kawasan bisnis dan lain-lain.

Selain Kabupaten Magelang dan Kota Surakarta, Kota Semarang secara geografis dan sosiologis memiliki daya tarik pariwisata dengan karakter dan keunikan tersendiri dibandingkan dengan kota kota lainnya di Indonesia. Kota Semarang memiliki kondisi geografis mulai dari 
daerah perbukitan sampai dengan daerah pantai sehingga memiliki potensi alam sebagai destinasi pariwisata bila dikelola dan dikembangkan dengan baik. Kota Semarang sendiri pada tahun 2015 menjadi kota dengan tingkat kunjungan wisatawan tertinggi ketiga di provinsi jawa tengah setelah Kabupaten Magelang dan Kota Surakarta. Kota Semarang yang menjadi destinasi utama wisatawan untuk berkunjung adalah Lawang sewu, Yang selama ini menjadi icon kota semarang dengan rata rata kunjungan per bulan mencapai 57.416 orang. Lawang sewu sendiri merupakan bangunan peninggalan belanda yang dibangun pada tahun 1904 dan selesai pada tahun 1907. Selain lawang sewu destinasi wisata yang sering dikunjungi lainnya adalah Pantai Marina. Pantai ini terletak disebelah timur Bandara Ahmad Yani Semarang yang jaraknya hanya beberapa ratus meter. Rata rata wisatawan yang berkunjung mencapai 39.077 orang per bulannya.

Kota Semarang merupakan kota multikultural yang terdiri dari berbagai macam etnis. Hal tersebut membuat Kota Semarang memiliki potensi seni budaya yang berlatar belakang pilar seni budaya masa lalu yag membentuk peradaban seni budaya Kota semarang saat ini yaitu Jawa, Cina, Arab dan Belanda.

Kabupaten Magelang sebagai daerah dengan jumlah kunjungan wisatawan terbanyak di jawa tengah dengan total 4.273.552 wisatawan yang berkunjung pada tahun 2015. Kabupaten Magelang memiliki 25 daya tarik wisata yang tersebar di seluruh kecamatan yang berada di kabupaten magelang. Fasilitas jalan ke obyek wisata sebagian besar sudah beraspal. Hanya satu yang belum yaitu daya tarik wisata Puthuk Setumbu yang tepatnya di kecamatan Borobudur akan tetapi meskipun belum beraspal akses jalan menuju puthuk setumbu sudah di beton sehingga memudahkan pengunjung yang akan berkunjung. Dilihat dari fasilitas yang sudah ada di masing masing daya tarik wisata hampir semuanya sudah memenuhi standar pelayanan seperti adanya jalan setapak sarana MCK, Pos Jaga dan Tempat parkir untuk mobil dan motor. Data Badan Pusat Statistik Jawa Tengah pada tahun 2012 sampai 2014 menunjukkan jumlah perkembangan hotel di Kabupaten Magelang masih tetap sama tanpa adanya penambahan yang signifikan. Tahun 2014 tercatat 8 hotel berbintang sedangkan hotel non bintang berjumlah 42 hotel.

Kota Surakarta sebagai daerah dengan jumlah kunjungan wisatawan terbanyak kedua di jawa tengah dengan total 3.007.329 wisatawan yang berkunjung pada tahun 2015. Kota Surakarta memiliki 8 daya tarik wisata yang tersebar di seluruh kecamatan yang berada di kota surakarta. Kondisi prasrana jalan menuju daya tarik wisata sudah beraspal sehingga memudahkan wisatawan yang hendak berkunjung. Selain itu daya tarik wisata yang tersebesar di setiap kecamatan di kota Surakarta memiliki harga tiket masuk yang masih terjangkau untuk semua kalangan pengunjung daya tarik tersebut. Rentang harga tket masuk yang ditawarkan mulai dari 3.000 hingga 35.000 ribu rupiah dengan fasilitas yang ditawarkan beraneka ragam.

Data dari Badan Pusat Statistik Jawa Tengah pada tahun 2014 jumlah hotel berbintang mencpai 33 hotel sedangkan non bintang pada tahun 2014 mencapai 114 hotel adapun jumlah restoran dan rumah makan pada tahun 2014 mencapai 267 tempat.

Kota Semarang sebagai daerah dengan jumlah kunjungan wisatawan terbanyak ketiga di jawa tengah dengan total $\mathbf{2 . 8 7 0 . 0 8 2}$ wisatawan yang berkunjung pada tahun 2015. Kota Surakarta memiliki 25 daya tarik wisata yang tersebar di 
seluruh kecamatan yang berada di kota semarang. Semarang adalah sebuah kota di pantai utara jawa yang memiliki akses tranportasi yang lengkap mulai dari bus kereta api pesawat hingga kapal. Semarang sebagai pusat pemerintahan jawa tengah memiliki banyak destinasi yang wajib dijadikan tujuan ketika melakukan perjalanan ke kota penghubungnya. Banyak tempat yang mempunyai keunikan serta potensi yang bisa lebih dikembangkan untuk destinasi wisata di kota semarang. Kondisi prasrana jalan menuju daya tarik wisata sudah beraspal dan ada yang menggunakan beton dan paving sebgai media jalnnya sehingga memudahkan wisatawan yang hendak berkunjung. Selain itu daya tarik wisata yang tersebesar di setiap kecamatan di Kota Semarang memiliki harga tiket masuk yang masih terjangkau untuk semua kalangan pengunjung daya tarik tersebut. Rentang harga tiket masuk yang ditawarkan mulai dari 2.000 hingga 60.00o ribu rupiah dengan fasilitas yang ditawarkan beraneka ragam. Data dari Badan Pusat Statistik Jawa Tengah pada tahun 2014 jumlah hotel berbintang mencpai 44 hotel sedangkan non bintang pada tahun 2014 mencapai 35 hotel adapun jumlah restoran dan rumah makan pada tahun 2014 mencapai 191 tempat.

Pengaruh Daya Tarik Wisata (DTW) terhadap keputusan wisatawan dalam menetukan destinasi wisata di Kabupaten Magelang Kota Surakarta Kota Semarang. Hasil

penelitian dari ketiga daerah tersebut didapatkan bahwa Daya Tarik Wisata Kabupaten Magelang dan Kota Semarang menunjukkan pengaruh yang signifikan terhadap keputusan wisatawan dalam menetukan destinasi wisata. Sedangkan daya tarik wisata Kota Surakarta tidak memiliki pengaruh yang nyata secara statistik terhadap keputusan wisatawan dalam menetukan destinasi wisata. Hal ini dengan dibuktikan jumlah daya tarik wisata yang berada di Kabupaten Magelang dan Kota Semarang jumlahnya lebih banyak dari Kota Surakarta. Berdasarkan data dari BPS Kota Surakarta hanya memiliki 8 tempat wisata dan 10 event wisata setiap tahunnya.

Pengaruh Aksesbilitas terhadap keputusan wisatawan dalam menetukan destinasi wisata di Kabupaten Magelang Kota Surakarta Kota Semarang. Berdasarkan hasil penelitian, variabel Aksesbilitas berpengaruh negatif terhadap keputusan wisatawan dalam menetukan destinasi wisata di Kabupaten Magelang dan Kota Semarang yang dapat diartikan bahwa Aksesbilitas tidak memiliki pengaruh yang nyata di Kabupaten Magelang dan Kota Semarang. Sedangkan Aksesbilitas pada Kota Surakarta memiliki pengaruh yang positif. Sehingga dapat diartikan bahwa Aksesbilitas pada kota surakarta memiliki pengaruh yang nyata secara statistik.

Pengaruh Sarana Prasarana terhadap terhadap keputusan wisatawan dalam menetukan destinasi wisata di Kabupaten Magelang Kota Surakarta Kota Semarang. Hasil penelitian menunjukkan sarana prasarana sektor pariwisata di Kabupaten Magelang dan Kota Semarang tidak signifikan terhadap keputusan wisatawan dalam menetukan destinasi wisata di Kabupaten Magelang dan Kota Surakarta. Yang artinya bahwa sarana prasarana yang ada pada objek wisata di Kabupaten Magelang dan Kota Surakarta tidak memiliki pengaruh yang nyata secara statistik, sehingga banyaknya sarana

prasarana tidak berpengaruh dalam meningkatkan keputusan wisatawan dalam menetukan destinasi wisata di Kabupaten Magelang dan Kota Surakarta. Sedangkan Kota 
Surakarta sendiri memiliki pengaruh yang signifikan dan dapat diartikan memiliki pengaruh yang nyata secara statistik. Kota Surakarta memiliki hasil signifikan dikarenakna sebagai kota budaya ketersedian fasilitas penunjang seperti hotel dan sarana tranportasi sangat dibutuhkan karena sebagaian besar wisatawan menginginkan kemudahan dan kenyamanan ketika akan menikamati cagar budaya yang ada.

Pengaruh Partisipasi Masyarakat terhadap keputusan wisatawan dalam menetukan destinasi wisata di Kabupaten Magelang Kota Surakarta Kota Semarang. Pengaruh partisipasi masyarakat terhadap keputusan wisatawan dalam menetukan destinasi wisata di Kabupaten Magelang Kota Surakarta kota Semarang menunjukkan bahwa partisipasi masyarakat di Kabupaten Magelang dan Kota Surakarta menunjukkan hasil yang signifikan terhadap keputusan wisatawan dalam menetukan destinasi wisata di kabupaten magelang dan kota surakarta.

Sedangkan partisipasi masyarakat pada kota semarang memiliki hasil yang tidak signifikan. Ketidak signifikannya hasil partisipasi masyarakat di Kota Semarang karena dalam pengelolaan tempat wisata dan penunjang wisata lainnya banyak yang bukan dikelola sendiri oleh masyarakat setempat hal ini yang membuat partisipasi masyarakat sekitar sendiri menjadi berkurang.

Berdasarkan tabulasi yang diperoleh dari pendapat beberapa key person menunjukkan bahwa kriteria aksesbilitas (nilai bobot 0.278 ) merupakan kriteria yang memiliki bobot paling tinggi, sehingga aksesbilitas perlu diperhatikan dalam meningkatkan kunjungan sektor pariwisata di Kabupaten Magelang Kota Surakarta dan Kota Semarang. Kriteria berikutnya adalah kriteria daya tarik wisata (nilai bobot 0.249), Sarana Prasarana (nilai bobot 0.243 ), dan kriteria partisipasi masyarakat (nilai bobot 0.229). Hal ini dapat dilihat berdasarkan tabel di bawah ini:

Tabel 1. Program Pengembangan Pariwisata Kabupaten Magelang, Kota Surakarta dan Kota Semarang

\begin{tabular}{|c|c|c|c|}
\hline \multirow[b]{2}{*}{ No } & \multicolumn{3}{|c|}{ Nilai } \\
\hline & Program & Bobot & Keterangan \\
\hline 1 & Daya & 0,249 & Inconsistency \\
\hline & Wisata & & Ratio $=0,00$ \\
\hline 2 & Aksesbilitas & 0,278 & \\
\hline & Menuju Daerah & & \\
\hline & Wisata & & \\
\hline 3 & $\begin{array}{l}\text { Sarana dan 0,243 } \\
\text { Prasarana }\end{array}$ & & \\
\hline 4 & $\begin{array}{l}\text { Partisispasi o,229 } \\
\text { Masyarakat }\end{array}$ & & \\
\hline
\end{tabular}

Sumber : Data Primer, diolah (2017).

Terpilihnya aspek aksesbilitas sebagai prioritas utama yang harus diperhatikan dalam upaya pengembangan pariwisata daerah mencerminkan bahwa pemerintah harus lebih memperhatikan aksesbilitas dikarenakan aksesbilitas yang baik menuju destinasi wisata dapat meningkatkan kunjungan masyarakat yang akan berkunjung.

Krieria pertama yang menjadi prioritas dalam pengembangan pariwisata daerah sebagai alternatif untuk meningkatkan kunjungan wisatawan adalah kriteria aksesbilitas. 
Tabel 2. Aspek Aksesbilitas Kabupaten Magelang, Kota Surakarta dan Kota Semarang

\begin{tabular}{llrl}
\hline No & \multicolumn{1}{c}{ Kriteria } & Nilai & Keterangan \\
& \multicolumn{2}{c}{ Bobot } & \\
\hline 1 & Ketersediaan & 0,643 & Inconsistency \\
transportasi & & Ratio $=$ o,oo \\
& menuju tempat \\
& & \\
2 & Jisata \\
& $\begin{array}{l}\text { Jaringan jalan o,357 } \\
\text { menuju daya tarik } \\
\text { wisata }\end{array}$ \\
\end{tabular}

Sumber : Data Primer, diolah (2017)

Berdsarkan hasil analisis AHP, maka dapat diketahui bahwa membangun sarana transportasi yang terintegritas dapat meningkatkan jumlah wisatawan yang berkunjung ke daerah yang memiliki daya tarik wisata. Transportasi pada sektor pariwisata merupakan alternatif yang paling prioritas dalam meningkatkan kunjungan sektor pariwisata pada aspek aksesbilitas dengan persentase prioritas sebesar $64,3 \%$.

Selanjutnya yang menjadi prioritas kedua dari aspek aksebilitias adalah menambah jaringna jalan disekitar lokasi objek wisata dengan persentase sebesar 35,7\%. Dari hasil ini telah didapat urutan alternatif sebagai strategi dalam meningkatkan kunjungan wisatawan pada sektor pariwisata di Kabupaten Magelang Kota Surakarta Kota Semarang dari aspek aksesbilitas.

Aspek kedua dalam strategi pengembangan pariwisata daerah sebagai alternatif untuk meningkatkan kunjungan wisatawan adalah aspek daya tarik wisata.
Tabel 3. Aspek Daya Tarik Wisata Kabupaten Magelang, Kota Surakarta dan Kota Semarang

\begin{tabular}{lrrr}
\hline No & Kriteria & $\begin{array}{c}\text { Nilai } \\
\text { Bobot }\end{array}$ & \\
& & Keterangan
\end{tabular}

\begin{tabular}{|c|c|c|}
\hline 1 & $\begin{array}{l}\text { Sumber } \quad \text { Daya 0,250 } \\
\text { Alam yang } \\
\text { berada } \\
\text { tempat wisata }\end{array}$ & $\begin{array}{l}\text { Inconsistency } \\
\text { Ratio }=0,00\end{array}$ \\
\hline 2 & $\begin{array}{l}\text { Sumber Daya 0,256 } \\
\text { Budaya yang } \\
\text { berada di } \\
\text { tempat wisata }\end{array}$ & \\
\hline 3 & $\begin{array}{l}\text { Kondisi o,250 } \\
\text { lingkungan } \\
\text { yang berada di } \\
\text { tempat wisata }\end{array}$ & \\
\hline 4 & $\begin{array}{l}\text { Atraksi } 0,244 \\
\text { pendukung } \\
\text { wisatayang } \\
\text { berada di } \\
\text { tempat wisata }\end{array}$ & \\
\hline
\end{tabular}

Sumber : Data Primer, diolah (2017)

Berdasarkan hasil pengolahan yang didapat dari analisis AHP dapat diketahui bahwa alternatif yang menjadi prioritas paling penting dalam meningkatkan kunjungan wisatawan sektor pariwisata dari aspek daya tarik wisata adalah mengembangkan sumber daya budaya yang berada di objek wisata yang ada dengan persentase sebesar 25,6\%. Selanjutnya prioritas alternatif kedua dari aspek daya tarik wisata adalah meningkatkan pengelolaan sumber daya alam yang ada di objek wisata guna menjaga dan 
merawat keindahan alaminya dengan persentase sebesar 25\%. Alternatif ketiga adalah Kondisi lingkungan daya tarik wisata tersebut. Prioritas ini saling berkaitan dengan prioritas kedua sumber daya alam dengan prensentasi yang dihasilkan sama sebesar $25 \%$. Prioritas alternatif yang paling akhir adalah mengembangkan atraksi pendukng yang berkaitan dengan sektor pariwisata yang ada dengan persentase sebesar $24,4 \%$.

Aspek ketiga yang perlu dipertimbangkan dalam pengembangan pariwisata daerah sebagai upaya untuk meningkatkan kunjungan wisatawan adalah kriteria sarana dan prasarana.

Tabel 4. Aspek Sarana dan Prasarana Kabupaten Magelang, Kota Surakarta dan Kota Semarang

\begin{tabular}{|c|c|c|c|}
\hline No & Kriteria & $\begin{array}{l}\text { Nilai } \\
\text { Bobot }\end{array}$ & Keterangan \\
\hline 1 & $\begin{array}{l}\text { Fasilitas } \\
\text { pendukung } \\
\text { daya tarik } \\
\text { wisata }\end{array}$ & 0,401 & $\begin{array}{l}\text { Inconsistency } \\
\text { Ratio }=0,07\end{array}$ \\
\hline 2 & $\begin{array}{l}\text { Fasilitas } \\
\text { pelayanan daya } \\
\text { tarik wisata }\end{array}$ & 0,261 & \\
\hline 3 & $\begin{array}{l}\text { Akomodasi } \\
\text { daya tarik } \\
\text { wisata }\end{array}$ & 0,339 & \\
\hline
\end{tabular}

Sumber : Data Primer, diolah (2017)

Dari hasil analisis AHP ini pada aspek sarana dan prasarana diketahui bahwa meningkatkan fasilitas pendukung wisata yang ada di objek wisata merupakan prioritas alternatif yang paling utama dengan persentase prioritas sebesar 40,1\%. Prioritas kedua dari aspek sarana dan prasarana adalah akomodasi disekitar objek wisata dengan persentase prioritas sebesar $33,9 \%$.
Dan prioritas ketiga dari aspek sarana dan prasarana adalah meningkatkan fasilitas pelayanan wisata yang ada di objek wisata dengan persentase prioritas sebesar $26,1 \%$.

Aspek terakhir yang perlu dipertimbangkan dalam pengembangan pariwisata daerah sebagai upaya untuk meningkatkan kunjungan wisatawan adalah kriteria partisipasi masyarakat.

Tabel 5. Aspek Partisipasi Masyarakat Kabupaten Magelang, Kota Surakarta dan Kota

\begin{tabular}{|c|c|c|c|}
\hline \multicolumn{4}{|c|}{ Semarang } \\
\hline No & Kriteria & $\begin{array}{l}\text { Nilai } \\
\text { Bobot }\end{array}$ & Keterangan \\
\hline 1 & $\begin{array}{l}\text { Aktivitas } \\
\text { masyarakat } \\
\text { sekitar objek } \\
\text { wisata }\end{array}$ & 0,286 & $\begin{array}{l}\text { Inconsistency } \\
\text { Ratio }=0,00\end{array}$ \\
\hline 2 & $\begin{array}{l}\text { Kepedulian } \\
\text { masyarakat } \\
\text { terhadap } \\
\text { lingkungan } \\
\text { sekitar objek } \\
\text { wisata }\end{array}$ & 0,714 & \\
\hline
\end{tabular}
Sumber : Data Primer, diolah (2017)

Berdasarkan analisis AHP menunjukkan bahwa prioritas pertama dari aspek partisipasi masyarakat dalam upaya meningkatkan kunjungan pada sektor pariwisata adalah kepedulian masyarakat terhadap lingkungan sekitar. dengan persentase sebesar $71,4 \%$. Selanjutnya prioritas kedua dari aspek partisipasi masyarakat adalah aktivitas masyarakat disekitar objek wisata dengan persentase sebesar $28,6 \%$.

\section{SIMPULAN}

Kabupaten Magelang Kota Surakarta dan Kota Semarang merupakan daerah yang memiliki potensi yang besar hal ini didukung oleh 
banyaknya obyek dan atraksi wisata yang tersebar hampir di setiap kecamatan dari ketiga daerah tersebut seperti Candi Borobudur di Magelang, Keraton Surakarta di Surakarta , dan Lawang Sewu di Kota Semarang dan merupakan beberapa daya tarik wisata yang bersifat internasional. Meskipun potensi daya tarik wisata cukup besar, namun sebagian besar dari daya tarik tersebut berskala kecil dengan fasilitas yang masih belum memadai dan belum terkelola secara maksimal.

Selain itu hasil penelitian menunjukkan keputusan wisatawan dalam menentukan destinasi wisata di Kabupaten Magelang dipengaruhi oleh aspek Daya Tarik Wisata dan Partisipasi Masyarakat di Kota Surakarta dipengaruhi oleh aspek Aksesbilitas, Sarana Prasarana dan Partisipasi Masyarakat sedangkan Kota Semarang dipengaruhi oleh aspek Daya Tarik Wisata. Selain itu hasil perhitungan strategi pengembangan pariwisata menunjukkan bahwa aksesbilitas merupakan kriteria utama dalam mengebangkan sektor pariwsata. Hal ini didukung melalui fakta dilapangan yang menunjukkan bahwa ksesbilitas sangat penting untuk memudahkan wisatawan yang hendak berkunjung ke daya tarik wisata. Hal ini diperlukan karena perlunya transportasi yang terintegrasi sampai ke pelosok daerah dikarenakan rata rata daya tarik wisata yang ada jauh dari pusat kota. Kriteria berikutnya adalah kriteria daya tarik wisata, kriteria sarana dan prasarana, dan kriteria partisipasi masyarakat.

\section{DAFTAR PUSTAKA}

Aries Susanty, Susatyo Nugroho, Adyan. 2015. Optimasi Pengembangan Kawasan Wisata di Semarang Dengan Menggunakan Metode Analytical Hierarchy Process, Analisis SWOT, Dan Multi-Attribute Utility Theory. Jurnal Teknik Industri. Volume 10. Nomor 2, Mei 2015 (diunduh 28 November 2016 Pukul 15:28).
Arikunto, Suharsimi. 2002. Prosedur Penelitian : Suatu Pendekatan Praktek. Jakarta: Rineka Cipta.

Ariyanto, 2005. Ekonomi Pariwisata. Jakarta : Penerbit Rineka Cipta

Badan Pusat Statistik Tengah. 2015. Distribusi Persentase PDRB Menurut Lapangan Usaha Atas Dasar Harga Konstan 2000 Provinsi Jawa Tengah Tahun 20102014. Provinsi Jawa Tengah: Badan Pusat Statistik.

Dinas Kebudayaan dan Pariwisata Provinsi Jawa Tengah. 2015. Pariwisata Dalam Angka 2015.

Gujarati, Damodar. 2003. Dasar-dasar Ekonometrika edisi Ketiga Jilid 2. Terjemahan Julius A.Mulyadi dan Yelvi Andri. Jakarta : Penerbit Erlangga.

I Ketut Surya Diarta, 2009. Pengantar Ilmu Pariwisata. Yogyakarta: Penerbit Andi.

J. Spillane. James. 1987. Ekonomi Pariwisata, Sejarah dan Prospeknya. Kanisius

Kementerian Pariwisata, 2015. Rencana Strategi Kementerian Pariwisata 2015-2019.

Nopirin. 20oo. Pengantar Ilmu Ekonomi Makro \& Mikro. Yogyakarta: BPFE.

Oka, A. Yoeti.20o8.Perencanaan Strategis Pemasaran Daerah Tujuan Wisata. Jakarta : Pradnya Paramita

Pradikta, Angga. 2013. Strategi Pengembangan Obyek Wisata Dalam Upaya Meningkatkan Pendapatan Asli daerah (PAD) Kabupaten Pati. Jurnal Ekonomi Pembangunan Volume 4. Nomer 1. Hlm. 246-256. (diunduh 28 Mei 2017 Pukul 11:53).

Prasetyo, P. Eko. 2009. Fundamental Makro Ekonomi. Yogyakarta: Beta Offset.

Ramadhan, Dede Setya. 2017. Strategi Pengembangan Obyek Wisata Puri Maerokoco Terhadap Pendapatan Sektor Pariwisata Kota Semarang. Jurnal Ekonomi Pembangunan Volume 2. Nomer 2. Hlm. 166-174. (diunduh 8 Juni 2017 Pukul 7:53).

Saaty, T.L. 1980. The Analytic Hierarchy Process.New York. USA: McGraw-Hil

Sefira Ryalita Primadany, Mardiyono, Riyanto. 2015. Analisis Strategi Pengembangan Pariwisata Daerah. Jurnal Administrasi Publik (JAP). Volume 1. Nomor 4. Hlm. 135-143. (diunduh 14 April 2016 Pukul 7:53).

Sucihatiningsih, DWP. 2013. Metode Analisis Efisiensi Produksi dan Pengambilan Keputusan Bidang Ekonomi Pertanian. Semarang: Unnes Press.

Suparmono. 2004. Pengantar Ekonomika Makro. Yokyakarta: UPP AMP YKPN.

Sugiyono. 2012. Metode Penelitian Kuantitatif, Kualitatif dan $R \mathcal{E} D$. Bandung: Alfabeta. 
Sutopo, HB, 2002. Metode Penelitian Kualitatif : Dasar

Teori dan

Penerapannya dalam Penelitian. UNS Press.

Surakarta

Suwantoro, Gamal. 2004. Dasar - Dasar Pariwisata. Jakarta: Andi Publisher.

Undang-Undang RI No.10 Tahun 2009. Tentang Kepariwisataan.Jakarta

Http://www.bpkp.go.id/unit/hukum/perpres/2005/200705.pdf> (3 Maret 2016)

Usman, Husaini dan Purnomo Setiady Akbar. 1995. Metodologi Penelitian Sosial. Jakarta: PT Bumi Aksara

Wahab, Salah. 2003. Manajemen Kepariwisataan. Jakarta: Pradnya Paramitha.

Wicaksono, Putra. 2012. Mementukan Jumlah Sampel dengan Rumus Slovin. http://analisisstatistika.blogspot.co.id/2012/o9/menentukanjumlah-sampel-dengan-rumus.html?m=1 (diunduh 8 Juni 2017 Pukul 8:29)

Widarjono, Agus. 2007. Ekonometrika Teori dan Aplikasi untuk Ekonomi dan Bisnis. Edisi kedua. Yogyakarta: Ekonisia.

Yoeti. Oka A, 1996. Pengantar Ilmu Pariwisata. Bandung : Angkasa. 